\title{
Climate Change Effects Management with the Approach of the Uncertainty of Atmosphere-Ocean General Circulation Models in Hamadan Province, Iran
}

\author{
Majid Ahmadi $^{1} \mathbb{D}, \underline{\text { Ghasem Azizi }}{ }^{2} \mathbb{D}$, Saeed Bazgir $^{3}$, Mohammad Hemmati ${ }^{4}$
}

Date of submission: 03 Oct. 2020 Date of acceptance: 07 Feb. 2021

\section{Original Article}

Abstract

INTRODUCTION: Since Iran is located in the semi-arid belt, it has faced such issues as drought, dust crisis, and intensified migration. The assessment of the effects of climate change includes identifying some key aspects of uncertainties used to estimate its impacts, such as uncertainties in the context of Atmosphere-Ocean General Circulation Models (AOGCMs): in regional-scale climatology, in statistical or dynamic downscaling methods, and parametric and structural uncertainties in different models. One of the most important sources of uncertainty in climate change is the use of different AOGCMs that produce different outputs for climate variables.

METHODS: In this study, to investigate the uncertainty of AOGCM models, the downscaled data of the NASA Earth Exchange Global Daily Downscaled Projections dataset obtained from 21 AOGCMs with medium Representative Concentration Pathway4.5 scenario were downloaded from the NASA site for 81 cells in Hamadan Province, Iran. After the validation of the models, they were evaluated against the criteria of the coefficient of determination and model efficiency coefficient in comparison with the data of the Hamedan synoptic station in the statistical period of 1976-2005. To reduce the uncertainty of AOGCMs, the ensemble performance (EP) of models was used in Climate Data Operators software.

FINDINGS: It was revealed that MRI-CGCM3, MPI-ESM-LR, BNU-ESM, ACCESS1-o, MIROCESM, MIROC-ESM-CHEM, and MPI-ESM-MR models had better performance than similar models. It was also found that IPSL-CM5A-LR, CNRM-CM5, CSIRO-Mk3-6-O, CESM1-BGC, and GFDL-ESM2M had the lowest correlation between observational and simulation data of mean monthly precipitation.

CONCLUSION: According to the results, this method could provide a good estimate in the base period (1976-2005), compared to the data of the Hamedan synoptic station, and was more accurate compared to the single implementation method of each AOGCM model. The results of EP of models in the future period (2020-2049) showed that precipitation will not change considerably in the future and will increase by $0.23 \mathrm{~mm}$. In addition, the average, maximum, and minimum annual temperatures will increase by $1.54^{\circ} \mathrm{C}, 1.7^{\circ} \mathrm{C}$, and $1.40^{\circ} \mathrm{C}$, respectively.

Keywords: Crisis Management; Climate Change; Hamadan Province; AOGCMs; Uncertainty

How to cite this article: Ahmadi M, Azizi GH, Bazgir S, Hemmati M. Climate change effects Management with the approach of the uncertainty of Atmosphere-Ocean General Circulation Models in Hamadan Province, Iran. Sci J Rescue Relief 2021; 13(1): 49-60.

\section{Introduction}

1. PhD student, Agricultural Meteorology, Kish International Campus, University of Tehran, Tehran, Iran

2. Professor of Climatology, Department of Physical Geography, Faculty of Geography, University of Tehran, Tehran, Iran

3. Assistant Professor of Agricultural Meteorology, Department of Physical Geography, Faculty of Geography, University of Tehran, Tehran, Iran

4.Assistant Professor, Department of Physical Geography, Yadegar-e-Imam Khomeini (RAH) Shahre Rey Branch, Islamic Azad University, Tehran, Iran

Correspondence to: Ghasem Azizi, Email: ghazizi@ut.ac.ir 
disasters and crises. Climate change is one of the 15 challenges of the next millennium in the world and one of the 7 main challenges of the future of Iran. Since Iran is located in the semi-arid belt, it has faced drought, dust crisis, intensified migration, floods, air pollution, landslides, extreme heat, extreme cold, and regional and local conflicts during the last two decades. Various predictions indicate that these consequences will be intensified in the future. These consequences can have different environmental, political, economic, social, and military-security dimensions.

In Iran, the effects of climate change and hazards have appeared for more than two decades; however, due to the gradual nature of the formation of hazards and negative effects of such hazards, as well as the dominance of empirical, habit-oriented, and non-futuristic approaches, the attention of the Iranian society was mostly drawn to the rapid and concentrated dangers, such as earthquakes, while the importance of the risks and damages and possible losses caused by climatic hazards, including drought, dust, and widespread floods, was neglected. Weakness in predicting the trends and possible effects of climate change and hazards in the past led to the growth of development planning and crisis and natural disaster management system in Iran incompatible with such disasters.

Hamedan Province, Iran, covering an area of $20,173 \mathrm{~km}^{2}$, is located in the west of Iran and includes 9 towns and 1,210 villages. This mountainous province is high and one of the cold provinces whose climate originates from its latitude, longitude, and elevation and distance from the sea. The climate of Hamedan Province is extremely variable due to the existence of high mountains and numerous uplands and lowlands. It also has cold and snowy winters and mild summers, which has created a suitable climate and fertile soil for agriculture. Figure 1 shows the position of Hamedan Province in Iran.

Climate change is the result of the external effects of nature and human beings; nevertheless, climate change originates from the internal processes of the climate system (1). The Intergovernmental Panel on Climate Change (IPCC), in its Fifth Assessment Report, used the new Representative Concentration Pathway (RCP) scenarios to represent the trajectories of different concentrations of greenhouse gases (2). At present, the most reliable tool for generating climate scenarios is the three-dimensional Atmosphere-Ocean General Circulation Model (AOGCM) (3).

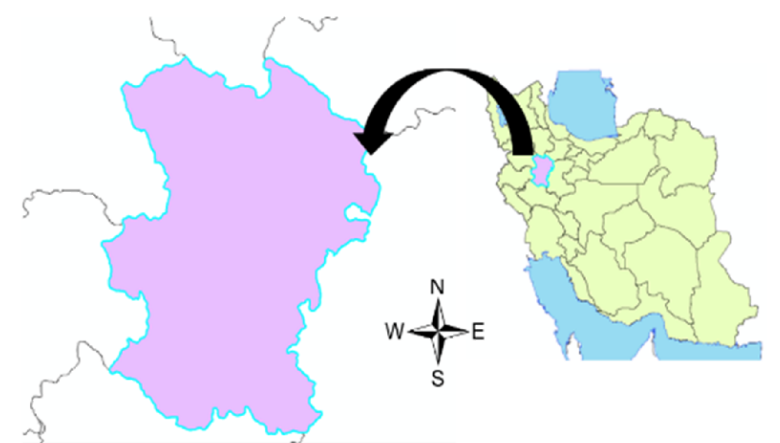

Figure 1. Location of Hamedan Province in the region

Although various studies have been conducted to investigate the effects of climate change on different systems and different approaches and how to reduce the damage, in most of these pieces of research, the existing uncertainties have been ignored and the analysis of the vulnerability of the systems to one or more scenarios of AOGCM models is considered sufficient. However, ignoring the uncertainties in the various stages of climate change impact assessment reduces the uncertainty of the final output of the system. One of the most important sources of lack of certainty in climate change is the application of different AOGCMs that produce various outputs for climate variables (4).

By considering the uncertainties, the results cover a range of possible future situations, which are sometimes highly different. Therefore, it is necessary to take into account the preparation for the changed conditions in the future while making decisions and adopting measures. Nonetheless, due to such limitations as limited access to data and computational costs, it is impossible to consider all uncertainties in all studies. In general, the use of several AOGCMs or approaches to ensemble performance (EP) of models to emphasize the uncertainty in weather forecasting, due to structural differences in global climate models as well as lack of certainty in changes in the initial conditions of the models, is one of the solutions to reduce the uncertainty of AOGCMs, which has been considered in this research. 
Ashraf et al. (2014) conducted a study to verify the temperature and precipitation data simulated by individual and group implementation of five AOGCMs for the northeastern region of Iran. For this purpose, they applied five models, namely the Benchmark Cost Model 2, Third Generation Coupled Global Climate Model (CGCM3), and CNRM-CM3 (Centre National de Recherches Météorologiques Climate Model) Model for Interdisciplinary Research on Climate (MIROC) 3.2, and Meteorological Research Institute Coupled Global Climate Model (MRICGCM) 2.3, and their EP. The results of the mentioned research showed that based on the individual implementation of the models, the MIROC 3.2, MRICGCM 2.3, and CNRMCM3 models could predict the precipitation more accurately in Torbat-e Heydariyeh, Sabzevar, and Mashhad, Razavi Khorasan Province, Iran, respectively.

Overall, the study of statistics calculated by EP of the five selected models showed a significant reduction in simulation error, which consequently, increased the accuracy of predictions (5). Jahanbakhsh Asl et al. (2016) performed a study to investigate and analyze the effects of climate change on temperature and precipitation in the Shahr Chay basin, Urmia, Iran. They concluded that the precipitation in the next period would be reduced by $9 \mathrm{~mm}$, while the minimum and maximum temperatures would increase by $1.05^{\circ} \mathrm{C}$ and $0.87^{\circ} \mathrm{C}$, respectively (6).

Rouhani et al. (2017) simulated rainfall time series with the output of Hadley Centre Coupled Model, version 3, NCPCM (NCAR/NSF/DOE/ NASA/NOAA Parallel Climate Model), CNCM3 (Centre National de Recherches Meteorologiques), GFCM3 (Geophysical Fluid Dynamics Lab, NOAA), and CGCM3 to investigate the uncertainty of simulation of rainfall time series in the first future horizon (2011-2040) and the second future horizon (20402070). The results showed that there was a significant difference in the simulation of some GCMs and emission scenarios, which was related to the CGCM3 in January and March and the GFCM3 model during the summer months (7).

Khazaei and Khazaei (2018) examined the magnitude and importance of uncertainties related to structures of GCMs and emission scenarios in the results of assessing the effect of climate change on the monthly flow of the Bashar River Basin, Yasuj, Iran. The findings of the mentioned research indicated that although the uncertainty of GCM models was greater than the uncertainty of the emission scenario, none of those uncertainties could be ignored in deciding for future basin plans (8).

Taban et al. (2018) evaluated the effect of uncertainty due to 10 general circulation models, statistical downscaling methods, and emission scenarios on the rainfall in the Upper Dez Basin (west part of Iran) in the circulation of 2040-2069. The results of comparing the emission scenarios in using the average of 10 climate models showed that the trend of difference in the range of percentage changes in the three emission scenarios for various months had close coordination with each other. The combined study showed that the uncertainties caused by different climate models used in the mentioned research were more than the uncertainties of the statistical downscaling methods and emission scenarios (9).

Wilby et al. (2006) examined the uncertainty of GCMs and emission scenarios in estimating the effect of climate change on daily runoff in England. They reported that the uncertainty resulting from the selection of GCMs was greater than that of emission scenarios (10). Wilby and Harris (2006) used four GCMs, emission scenarios, different statistical downscaling methods, and two hydrological methods in the Thames Basin, England, to investigate more sources of uncertainty. Accordingly, they concluded that the highest uncertainty was related to choosing GCM (2).

Cameron (2006) examined the uncertainty of GCMs, emission scenarios, and climate fluctuations in assessing the effect of climate change on floods of a basin in Scotland. The results of the mentioned research revealed that it was essential to use more than one GCM in such studies (11). Graham et al. (2007) used two GCMs, two Regional Circulation Models (RCMs), and two emission scenarios in order to assess the uncertainties in the effects of climate change on the flow of the Lule River Basin in Sweden. They concluded that the greatest uncertainty was related to the choice of GCM (12).

In another study, Prudhomme and Davies (2008) examined the uncertainties in assessing the effect of climate change on monthly flow in four basins. Based on the findings of the mentioned research, the largest source of uncertainty was related to GCMs (1). Fowler and Ekström (2009) also investigated the effect of climate change on 
extreme precipitation in England within 2100-2070 by EP of 13 RCMs based on the weight method. They reported a significant reduction in errors of models, and therefore, a decrease in the uncertainty of precipitation prediction (13).

Chilkoti et al. (2017) used the multiple EP (MEP) method for a number of models to reduce the uncertainty of GCMs in estimating the effect of climate change on river flow (14). In another research, Naz et al. (2018) applied the MEP for several models to implement $10 \mathrm{GCMs}$ in the United States (15). Wang et al. (2019) evaluated the effect of climate change on temperature and precipitation. The results indicated that the MEP of a number of models could reduce the uncertainty of GCMs. They investigated the effect of climate change on temperature and precipitation in Xiangjiang Basin, China and used 14 GCMs under the RCP4.5 scenario to accomplish this aim. Accordingly, they reported that the temperature will increase during the next period in 2050 and precipitation will decrease and increase during the periods of 2020 and 2030, respectively (16).

Thompson et al. (2019) used 7 GCMs to investigate the uncertainty of emission scenarios in estimating the effect of climate change on the flow of 87 hydrometric stations in Southeast Asia and found that there were significant differences among the results of applying various GCMs (17). Xu et al. (2019) investigated the uncertainty of $18 \mathrm{GCMs}$ and emission scenarios in predicting maximum precipitation in China and, for this purpose, used EP methods to reduce the uncertainty of forecasts. The results of the aforementioned research showed that the uncertainty of GCMs was much greater than the emission scenarios. Moreover, the precipitation will be more intense and shorter within 2100-2020, which will be much more severe in RCP8.5 (18).

According to the above explanations, the present study was conducted to investigate the uncertainty of AOGCMs of downscaled data of the NASA Earth Exchange Global Daily Downscaled Projections (NEX-GDDP) dataset obtained from 21 AOGCMs with RCP4.5 scenario in Hamadan Province. Furthermore, in order to reduce the uncertainty of AOGCMs, the MEP method was applied.

\section{Methods}

Production of climate change scenarios in the future (2020-2049) using AOGCMs

Currently, the most common tool for generating climate scenarios is the AOGCM (2). In order to simulate the Earth's climate, the main components of the climate system (i.e., atmosphere, hydrosphere, lithosphere, cryosphere, and biosphere) are simulated in separate sub-models. Afterward, all sub-models related to the atmosphere and hydrosphere are paired together to form AOGCMs (1). In this section, the downscaled data of the NEX-GDDP dataset were downloaded from the NASA site for 81 cells in Hamadan Province using the Bias Corrected Spatial Downscaling (BCSD) method obtained from 21 AOGCMs with a medium scenario of RCP4.5. The BCSD method consists of two steps to complete the statistical downscaling:

\section{Step One: Bias}

In this step, GCM data are corrected through comparisons with previous Global Meteorological Forcing Dataset (GMFD) data. For each climatic variable on a specific day, it generates the cumulative distribution function (CDF) algorithm for GMFD data and previous GCM simulations after collecting and sorting baseline values $(+/-15$ days) during the period of 1950 to 2005 . Subsequently, it compares the two CDFs with different probability thresholds to create an approximate map (quantile) between GCM data and past climate data.

According to this map, GCM values in each CDF quantile (for example, $\mathrm{P}=90 \%$ ) can be translated to the corresponding GMFD value in the same CDF quantile. Assuming that the CDF simulation of GCM remains stable in past and future periods, to correct the prediction of future climate change, the algorithm searches for the quantile probability associated with the predicted climate values of the GCM CDF. It then accepts these predicted values as adjusted climate forecasts.

Modified climate forecasts have a CDF similar to GMFD data; therefore, the possible biases in the statistical structure (especially variance) cause the elimination of the original GCM outputs in this method. At the end of the bias correction step, the previously extracted climatic trend is added to the modified GCM fields (4).

\section{Step 2: Spatial disaggregation}

The second step is the spatial disaggregation of the modified GCM data into the grid with a resolution of GMFD data of $0.25^{\circ}$. In addition to the simple linear spatial interpolation algorithm, 
several steps are performed in the signed-digit (SD) algorithm to preserve the spatial details of the observational data. Initially, several decades of daily climatic data of GMFD variables (i.e., temperature and precipitation) are generated in two main resolutions, namely original and GCM. Climatology for the SD step is the average calculated for each day of the year in the base period, 1950-2005. Subsequently, for each time step, the algorithm compares the modified GCM variables with the corresponding GMFD climatology to calculate the scaling factors. Scaling factors are calculated as the difference between the bias-modified GCM and the GMFD data for temperature; however, for precipitation, scaling factors are calculated as a proportion to avoid negative values. Thirdly, large-resolution scaling factors are interpolated into highresolution GMFD networks by the two-line method.

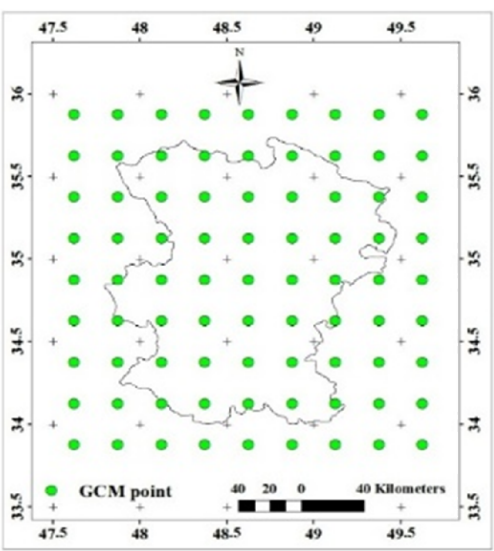

Figure 2. Extracted points for each of the AOGCM models in Hamadan Province

Finally, scale factors are applied by adding or transmitting temperature and multiplication for precipitation on high-resolution GMFD climatology to achieve the desired downscaling. Similarly, the algorithm combines the past spatial climatic observations with relative changes in each step simulated by GCMs to produce the final results (4). These data include daily precipitation data (in $\mathrm{kg} / \mathrm{m}^{2} / \mathrm{sec}$ ) and maximum and minimum temperatures (in ${ }^{\circ} \mathrm{K}$ ) for the base period (19762005) and the future period (2020-2049) for 21 AOGCMs. The downloaded files are in Network Common Data Form format and the basis of the World Geodetic System-84 coordinate system with a spatial scale of 0.25 degrees. These files were processed in Climate Data Operators software in the Linux operating system using different command lines, and finally, precipitation (in $\mathrm{mm}$ ) and temperature (in ${ }^{\circ} \mathrm{C}$ ) data were extracted for the baseline and future periods for 21 AOGCMs. Figure 2 depicts the extracted points for each of the AOGCMs at the provincial level.

\section{Validation of temperature and precipitation data of AOGCMs in the base period (1976-2005)}

Given the importance of climate models as the main tools used to investigate climate change and due to the multiplicity of such models, the selection of the most appropriate models for the study area was of considerable importance. To the best of our knowledge, few studies have been conducted to address this domain. Therefore, it is necessary to carry out pieces of research on the validation of these models to minimize the uncertainties in climate forecasts.

To validate AOGCMs, firstly, the coefficient of determination $\left(\mathrm{R}^{2}\right)$ and the model efficiency coefficient (ME) were calculated to compare the temperature and precipitation data simulated by the models based on the RCP4.5 emission scenario and the actual values recorded in the synoptic station in Hamedan Province (19).

The model efficiency coefficient was introduced by Nash and Sutcliffe in 1970. The resulting values are dimensionless and vary from negative infinity to 1 , with closer values to 1 indicating greater coordination between the two series. The Nash and Sutcliff method is calculated as Equation 1:

$$
\mathrm{ME}=1-\frac{\sum_{\mathrm{i}=1}^{\mathrm{n}}\left(\mathrm{S}_{\mathrm{sim}}-\mathrm{O}_{\mathrm{obs}}\right)^{2}}{\sum_{\mathrm{i}=1}^{\mathrm{n}}\left(\mathrm{O}_{\mathrm{obs}}-\overline{\mathrm{O}}_{\mathrm{obs}}\right)^{2}}
$$

The coefficient of determination is the proportion of the variance in the dependent variable. That is predictable from the independent variable(s). (Equation 2), with closer values to 1 showing a better expression of relationships between the two parameters by the obtained regression equation (20).

$$
\mathrm{R}^{2}=\left[\frac{\sum_{\mathrm{i}=1}^{\mathrm{n}}\left(\mathrm{O}_{\mathrm{obs}}-\overline{\mathrm{O}}\right)\left(\mathrm{S}_{\mathrm{sim}}-\overline{\mathrm{S}}\right)}{\sqrt{\sum_{\mathrm{i}=1}^{\mathrm{n}}\left(\mathrm{O}_{\mathrm{obs}}-\overline{\mathrm{O}}\right)^{2} \sum_{\mathrm{i}=1}^{\mathrm{n}}\left(\mathrm{S}_{\text {sim }}-\overline{\mathrm{S}}\right)^{2}}}\right]^{2}
$$

In this equation, $\mathrm{O}_{\mathrm{obs}}=$ observational data, $\overline{\mathrm{O}}=$ mean observational data, $\mathrm{S}_{\mathrm{sim}}=$ simulated data, $\overline{\mathrm{S}}=$ mean observational data, and $\mathrm{n}=$ number of data (21). 


\section{Reduction of model uncertainty with applying ensemble performance methods}

The ignorance of the uncertainties associated with climate change in studies will reduce the validity of the results and lead to the application of unrealistic and impractical results to users. Recently, the implementation of EP has been recommended by the IPCC to decrease the uncertainties of climate forecasts (22). The MEP is one of the methods used to reduce prediction uncertainties that can be calculated in different ways, including the weight method (22). According to this method, first, the calculated weight of the models $\left(\mathrm{W}_{\mathrm{i}}\right)$, based on Equation 3, is multiplied by their mean values in the desired month $\left(\mathrm{M}_{\mathrm{i}}\right)$ and then the resulting values are added together according to Equation 4 (10):

$$
\begin{gathered}
\mathrm{W}_{\mathrm{i}}=\frac{\left(\frac{1}{\Delta \mathrm{F}_{\mathrm{i}}}\right)^{2}}{\sum_{\mathrm{i}=1}^{\mathrm{n}}\left(\frac{1}{\Delta \mathrm{F}_{\mathrm{i}}}\right)^{2}} \\
\mathrm{E}=\sum_{\mathrm{i}=1}^{\mathrm{n}} \mathrm{W}_{\mathrm{i}} \mathrm{M}_{\mathrm{i}}
\end{gathered}
$$

In this equation, $\mathrm{W}_{\mathrm{i}}$ is the weight of each model in the desired month and $\Delta \mathrm{F}_{\mathrm{i}}$ is the longterm mean deviation of the simulated variable by each of the models in the base period from the mean of actual or observed data, and $n$ is the number of models.

\section{Findings}

The validation of temperature and precipitation data obtained from AOGCMs in the base period (1976-2005) regarding the evaluation of the accuracy of AOGCMs was performed by firstly the calculation of $\mathrm{R}^{2}$ and $\mathrm{ME}$ to compare the temperature and precipitation simulated by AOGCMs and the actual values recorded at the synoptic station in Hamedan Province during the base period (1976-2005) (Table 1).

The results showed that MRI-CGCM3, MPIESM-LR, BNU-ESM, ACCESS1-0, MIROCESM, MIROC-ESM-CHEM, and MPI-ESM-MR models had better performance in simulation. Furthermore, it was revealed that IPSL-CM5A-LR, CNRM-CM5, CSIRO-Mk3-6-0, CESM1-BGC, and GFDL-ESM2M had the lowest correlation between the observational and simulated data of mean monthly precipitation.

\begin{tabular}{|c|c|c|c|c|c|c|}
\hline \multirow{2}{*}{ AOGCMs } & \multicolumn{2}{|c|}{ Precipitation } & \multicolumn{2}{|c|}{ Maximum temperature } & \multicolumn{2}{|c|}{ Minimum temperature } \\
\hline & $\mathbf{R}^{2}$ & ME & $\mathbf{R}^{2}$ & ME & $\mathbf{R}^{2}$ & ME \\
\hline ACCESS1-0 & 0.93 & 0.88 & 0.94 & 1 & $0 / 94$ & 1 \\
\hline BCC-CSM-1-1 & 0.75 & 0.72 & 0.54 & $0 / 67$ & $0 / 54$ & $0 / 61$ \\
\hline BNU-ESM & $0 / 83$ & $0 / 90$ & $0 / 69$ & $0 / 96$ & $0 / 69$ & $0 / 94$ \\
\hline $\begin{array}{c}\text { CanESM2 } \\
\text { CCSM4 }\end{array}$ & $\begin{array}{l}0 / 91 \\
0 / 71\end{array}$ & $\begin{array}{l}0 / 77 \\
0 / 73\end{array}$ & $\begin{array}{l}0 / 89 \\
0 / 94\end{array}$ & $\begin{array}{l}0 / 67 \\
0 / 67\end{array}$ & $\begin{array}{l}0 / 89 \\
0 / 94\end{array}$ & $\begin{array}{l}0 / 61 \\
0 / 61\end{array}$ \\
\hline CESM1-BGC & $0 / 65$ & $0 / 61$ & $0 / 60$ & $0 / 67$ & $0 / 60$ & $0 / 60$ \\
\hline CNRM-CM5 & $0 / 68$ & $0 / 64$ & $0 / 65$ & 1 & $0 / 65$ & 1 \\
\hline CSIRO-Mk3-6-0 & $0 / 61$ & $0 / 63$ & $0 / 68$ & $0 / 67$ & $0 / 68$ & $0 / 60$ \\
\hline GFDL-CM3 & $0 / 72$ & $0 / 70$ & $0 / 67$ & $0 / 69$ & $0 / 67$ & $0 / 63$ \\
\hline GFDL-ESM2G & $0 / 73$ & $0 / 73$ & $0 / 59$ & $0 / 71$ & $0 / 59$ & $0 / 64$ \\
\hline GFDL-ESM2M & $0 / 61$ & $0 / 60$ & $0 / 60$ & $0 / 71$ & $0 / 60$ & $0 / 64$ \\
\hline INM-CM4 & $0 / 71$ & $0 / 71$ & $0 / 60$ & $0 / 66$ & $0 / 60$ & $0 / 60$ \\
\hline IPSL-CM5A-LR & $0 / 65$ & $0 / 68$ & $0 / 60$ & $0 / 67$ & $0 / 60$ & $0 / 61$ \\
\hline IPSL-CM5A-MR & $0 / 70$ & $0 / 72$ & $0 / 95$ & $0 / 67$ & $0 / 95$ & $0 / 61$ \\
\hline MIROC5 & $0 / 76$ & $0 / 77$ & $0 / 95$ & $0 / 67$ & $0 / 95$ & $0 / 60$ \\
\hline MIROC-ESM & $0 / 91$ & $0 / 84$ & $0 / 95$ & 1 & $0 / 95$ & 1 \\
\hline MIROC-ESM-CHEM & $0 / 84$ & $0 / 84$ & $0 / 95$ & 1 & $0 / 95$ & 1 \\
\hline MPI-ESM-LR & $0 / 87$ & $0 / 91$ & $0 / 94$ & 1 & $0 / 94$ & 1 \\
\hline MPI-ESM-MR & $0 / 82$ & $0 / 82$ & $0 / 94$ & 1 & $0 / 94$ & 1 \\
\hline MRI-CGCM3 & $0 / 73$ & $0 / 93$ & $0 / 58$ & 1 & $0 / 58$ & 1 \\
\hline NorESM1-M & $0 / 71$ & $0 / 71$ & $0 / 60$ & $0 / 66$ & $0 / 60$ & $0 / 61$ \\
\hline
\end{tabular}

Table 1. Validation of AOGCMs and results of the coefficient of determination and model efficiency coefficient 


\section{Reduction of model uncertainty using ensemble performance methods}

In the current research, the EP method was applied in order to increase the accuracy of the results and reduce the uncertainty of AOGCMs. The results of $\mathrm{R}^{2}$ and ME of this method in the base period (1976-2005) in comparison with the data obtained from the synoptic station in Hamedan Province are presented in Table 2.

The results of statistical coefficients of ensemble performance method showed that this method in the base period (1976-2005) provided a good estimate, in comparison with the data of Hamadan synoptic station. It was also revealed that it had much more accuracy than the single implementation of each AOGCM. Finally, after the ensemble performance of AOGCMs for the future period (2020-2049), the average annual changes of temperature and precipitation parameters in the future period (2020-2049) were compared with the base period (1976-2005) (Table 3).

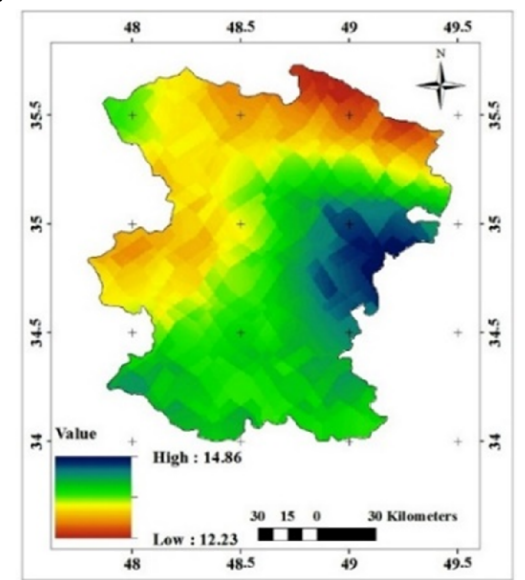

Figure 3. Average annual precipitation in the future period (2020-2049) in Hamadan Province

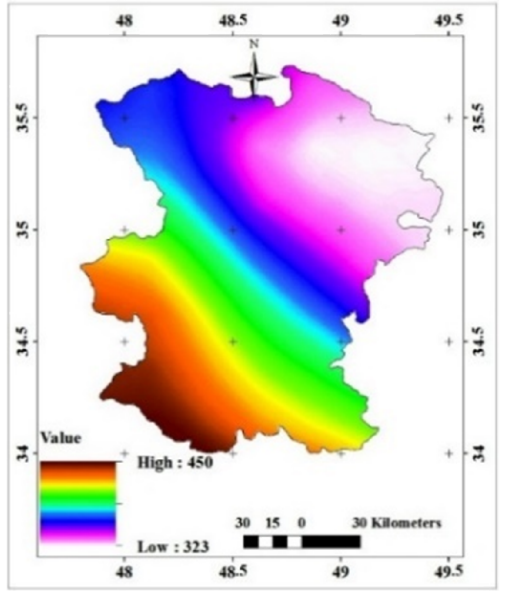

Figure 4. Average annual temperature in the future period (2020-2049) in Hamadan Province
The results of the ensemble performance of models in the future period (2020-2049) indicated that precipitation will not change considerably in the future and will increase by $0.23 \mathrm{~mm}$. However, the average, maximum, and minimum annual temperatures will increase by $1.54^{\circ} \mathrm{C}$, $1.7^{\circ} \mathrm{C}$, and $1.40^{\circ} \mathrm{C}$, respectively. Figures 3 and 4 depict the average monthly and annual temperature and precipitation parameters in the EP method of models during the future period in Hamadan province.

The examination of average annual temperature and precipitation maps in the future period (2020-2049) in Hamadan Province showed that the rainfall changes follow an increasing trend from northeast to southwest and the highest rainfall will occur in the southwest of this province.

Nevertheless, in terms of temperature, this trend will be reversed, meaning that it will increase from northwest to east, and the highest temperature will be observed in the east of the province at $14.86^{\circ} \mathrm{C}$. Figures 5 and 6 show the comparisons of average monthly and seasonal precipitation during the base period (1976-2005) and the future one (2020-2049).

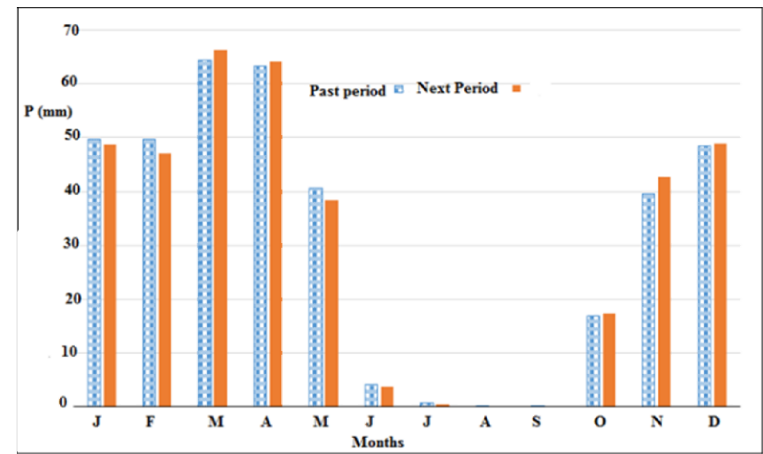

Figure 5. Comparison of average monthly precipitation during the base and future periods

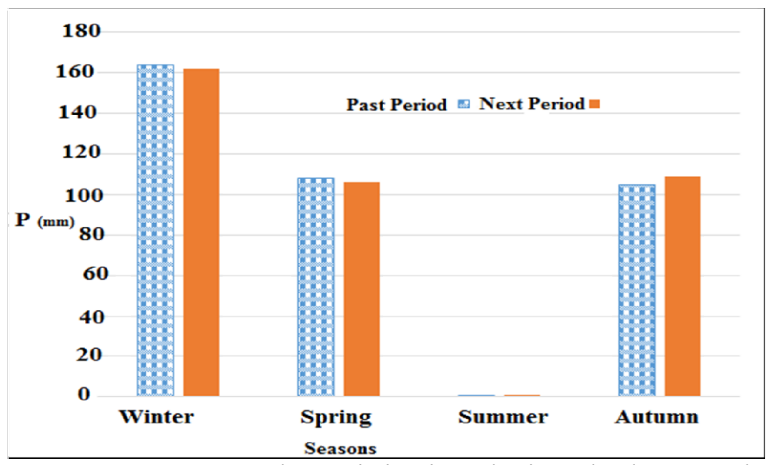

Figure 6. Seasonal precipitation during the base and future periods in Hamedan Province 

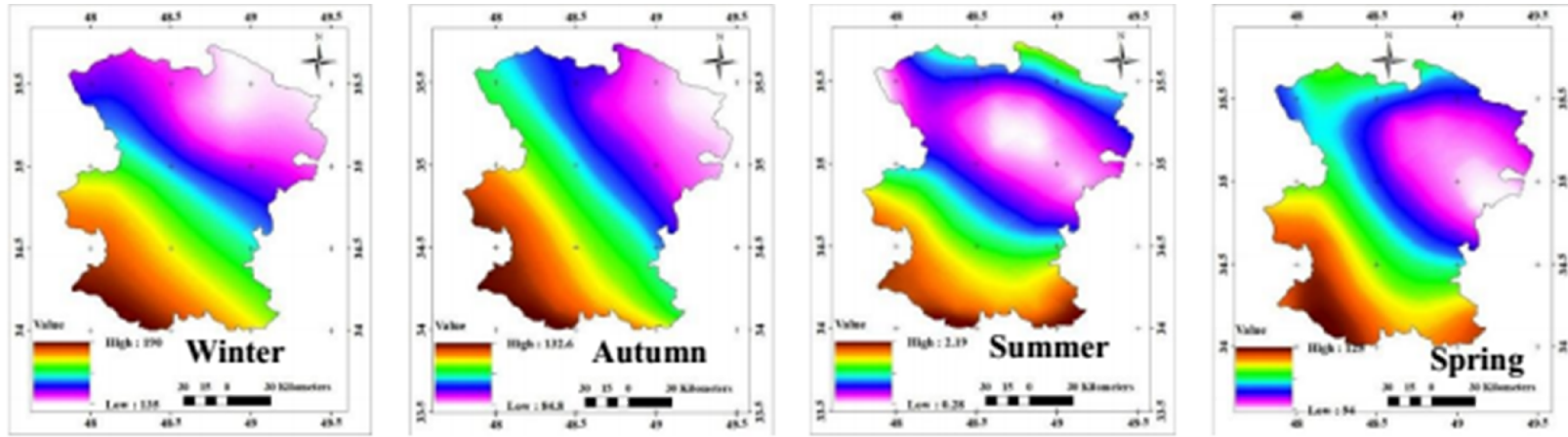

Figure 7. Average seasonal precipitation in the future period (2020-2049) in Hamadan Province
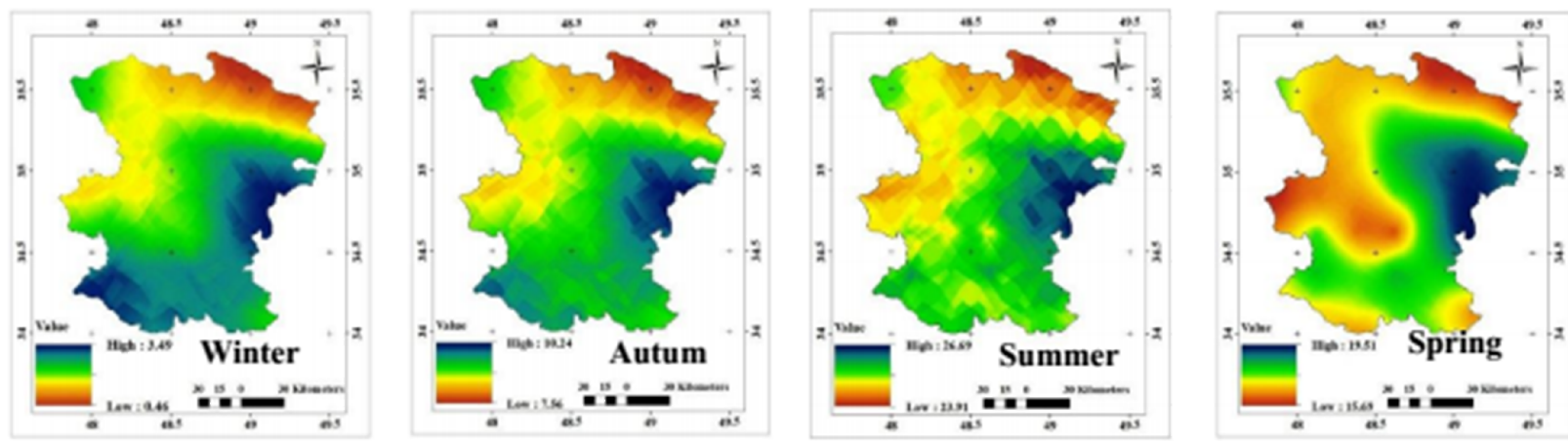

Figure 8. Average temperature in spring in the future period (2020-2049) in Hamadan Province

The average seasonal precipitation and temperature in the future period (2020-2049) are presented in figures 7 and 8 . According to the seasonal rainfall maps, in spring, the highest and lowest rainfall amounts will occur in the southwest of the province at $125 \mathrm{~mm}$ and $94 \mathrm{~mm}$, respectively. It was also found that, in summer, autumn, and winter, this amount will be between 2.19 and $0.28 \mathrm{~mm}, 132.6$ and $84.8 \mathrm{~mm}$, and 190 and $135 \mathrm{~mm}$, respectively.
Generally, it is expected that the average annual temperature of the province will increase by about $1.54^{\circ} \mathrm{C}$ in the future period, compared to the base period. It is also evident that the highest temperature increase belongs to the spring and summer seasons. The average changes of minimum and maximum temperatures in the mentioned statistical period have an increasing trend.

Table 2. Results of the coefficient of determination and model efficiency coefficient of ensemble performance method of models in comparison with Hamedan synoptic station data in the base period (1976-2005)

\begin{tabular}{|c|c|c|c|c|c|c|}
\hline $\begin{array}{c}\text { Model evaluation } \\
\text { criteria }\end{array}$ & Precipitation & $\begin{array}{c}\text { Maximum } \\
\text { temperature }\end{array}$ & $\begin{array}{c}\text { Minimum } \\
\text { temperature }\end{array}$ & $\begin{array}{c}\text { Precip } \\
\text { itation }\end{array}$ & $\begin{array}{c}\text { Maximum } \\
\text { temperature }\end{array}$ & $\begin{array}{c}\text { Minimum } \\
\text { temperature }\end{array}$ \\
\hline $\begin{array}{c}\text { Ensemble } \\
\text { performance method } \\
\text { of models }\end{array}$ & 0.95 & 0.97 & 0.96 & 0.92 & 0.95 & 0.95 \\
\hline
\end{tabular}

Table 3. Average monthly and annual changes of temperature and precipitation parameters in the ensemble performance method of models

\begin{tabular}{c|cccc|} 
Climatic period & Precipitation & $\begin{array}{c}\text { Maximum } \\
\text { temperature }\end{array}$ & $\begin{array}{c}\text { Minimum } \\
\text { temperature }\end{array}$ & $\begin{array}{c}\text { Medium } \\
\text { temperature }\end{array}$ \\
\hline Base period (1976-2005) & 377.81 & 20.3 & 3.50 & 11.98 \\
Future period (2020-2049) & 378.04 & 22 & 4.90 & 13.43 \\
Average rate of changes & +0.23 & +1.7 & +1.40 & +1.54 \\
\hline
\end{tabular}




\section{Discussion and conclusion}

Accurate prediction of climate change is the most important step in dealing with and reducing the negative effects of climate change and the proper management of the resulting crises. To achieve the most accurate forecast, it is necessary to first identify the most appropriate model for each region and then predict the climate changes. The results of investigating the accuracy of 21 AOGCMs using statistical indicators in the base period (1976-2005) showed that each of the models revealed different estimations of precipitation and temperature during this period, indicating the fact that it is not possible to rely solely on one or more AOGCMs to predict future climatic conditions. Therefore, it is required to review all existing models and validate them to minimize forecast errors.

It was found among the studied 21 models, the MRI-CGCM3, MPI-ESM-LR, BNU-ESM, ACCESS1-0, MIROC-ESM, MIROC-ESMCHEM, and MPI-ESM-MR models could offer the best predictions of precipitation and temperature parameters in the base period. The results of the present study showed that in a region, the same model does not necessarily provide the most accurate forecast for all climatic parameters and the best prediction for temperature and precipitation parameters in that region may be made by applying several different models. It is also possible that in two different areas of a basin understudy, a model has the lowest and highest errors in simulating temperature and precipitation parameters.

Based on the results of validation of 21 AOGCMs, each of the AOGCMs provided a different estimate of the climatic conditions in the base period, and the accuracy of these models was different. Consequently, the EP was used in this study to increase the accuracy of the results and reduce the uncertainty of AOGCMs. The results of statistical coefficients of the EP method showed that this method could provide a good estimate in the basic period (1976-2005), in comparison with the data obtained from Hamadan synoptic station for the same period. It was also revealed that compared to the single implementation method, each of the AOGCMs had much more accuracy, could provide a much more accurate estimation of future environmental conditions, and had less uncertainty.
In reviewing the results of the calculated statistics for EP of models, it was observed that the implementation of a set of different models could significantly increase the accuracy of climatic forecasts, or in other words, reduce the associated uncertainties, compared to using a single model. The results of the current research are consistent with those reported in the studies conducted by $\mathrm{Xu}$ et al. (2019), Thompson et al. (2019), Wang et al. (2019), Naz et al. (2018), Graham and et al. (2007), Cameron (2006), ). Fowler and Ekström (2009), and Ashraf et al. (2014), showing a significant reduction in prediction uncertainty, compared to using a single model. In these studies, it has been acknowledged that different AOGCMs produce various predictions, and it has been stated that the range of uncertainty of these models is much wider than other sources of uncertainty. It is recommended that more than one AOGCM be used in studies investigating climate change to reduce forecast uncertainty.

Gholampour et al. (2019) studied the current climate change trend and projection of Coupled Model Intercomparison Project Phase 5 climate models under the Coordinated Regional Downscaling Experiment project in rainfed areas of Kurdistan Province, Iran. They found that the current trend of climate change using the MannKendall test and Sen's slope estimator indicated a decrease in rainfall and an increase in temperature and reference evapotranspiration of the plant (23).

Considering the proximity of the two provinces of Hamedan and Kurdistan, Iran, and expecting relatively similar results, in both provinces an increase will be observed in temperature in the long-run; however, in terms of precipitation, an increase will be observed only in Hamedan in the future, although in low amounts. The reason for this discrepancy can be largely attributed to both environmental factors and the type of model used to investigate climate change.

A closer look at this issue shows that environmental variables have undeniable roles in the amount and distribution of precipitation. Moreover, differences in the amount and type of precipitation and rainfall systems in neighboring areas are justifiable due to the involvement of local factors, especially topographic and geographical features of the region. In this respect, it can be concluded that these factors are undoubtedly included in the physical structure of 
the optimal models and have been effective in their final estimates.

The selected models in this study showed sensitivity to the least climatic and geographical changes, which is a highly positive point and significant in investigating a region with similar geographical features and lack of great climatic diversity, as the studied area in this research. Considering the results of the present study, it is suggested that in all studies being conducted with the aim of making predictions of climate change or investigating its effects in different regions, first the optimal model of that region be selected separately for each parameter under consideration to obtain the most realistic results for presentation to the executive departments. In addition, due to the multiplicity of climate models and easy access to their output data in a short time, it is recommended to use as many models as possible instead of one model in climate change studies to reduce the uncertainty of the predictions to an acceptable level.

In the same vein, merely the use of the output of AOGCM cannot produce logical results for planning to reduce the destructive effects of climate change. On the other hand, the application of a set of different models can significantly increase the accuracy of climate forecasts, or in other words, reduce the associated uncertainties, compared to using only one model. The combination of predictions made by different models using the Bayes theory can also be used as another appropriate solution to improve the results. Furthermore, skewed removal of data using statistical and probabilistic methods can greatly reduce the error of predictions.

The results of EP of models in the future period (2020-2049) showed that precipitation will not change considerably in the future and will increase by $0.23 \mathrm{~mm}$. However, the average, maximum, and minimum annual temperatures will increase by $1.54^{\circ} \mathrm{C}, 1.7^{\circ} \mathrm{C}$, and $1.40^{\circ} \mathrm{C}$, respectively. Regarding the precipitation changes, it follows an increasing trend from northeast to southwest and the highest rainfall will occur in the southwest

of this province. Nevertheless, in terms of temperature, this trend will be reversed, meaning that it will increase from northwest to east, and the highest temperature will be observed in the east of the province at $14.86^{\circ} \mathrm{C}$. Generally, it is expected that the average annual temperature of the province will increase by about $1.54^{\circ} \mathrm{C}$ in the future period, compared to the base period. It is also evident that the highest temperature increase belongs to the spring and summer seasons.

The average changes of minimum and maximum temperatures in the mentioned statistical period have an increasing trend. Hashemi Ana et al. (2017) evaluated the capability of AOGCMs in simulating the length of dry periods with the approach of studying uncertainty and climate change in Iran. The comparison of the results of the mentioned study with those of the present research revealed that the investigation of uncertainty during the dry periods in Iran was indicative of the increase of dry periods length in all areas of Iran in both 2050s and 2080s based on all three scenarios (i.e., $\mathrm{B} 1, \mathrm{~A} 1 \mathrm{~B}, \mathrm{~A} 2)$.

The highest percentage of changes during the length of dry periods was related to the northwest cities, namely Urmia, Khoy, Kermanshah, Hamedan, and Lorestan, Iran. Considering the fact that the present study was focused on Hamedan Province, the result of the aforementioned research conducted in Hamedan Province is consistent with those of the present study (24).

Based on the results of the current study, generally, there will be an increase in temperature and a decrease in rainfall, which may result in changes in snowfall, snow melting, and rainfall intensity in many parts of the province. Moreover, it can cause changes in the net amount and seasonal pattern of available water resources and the occurrence of sudden floods in the region due to increased rainfall, which eventually, will lead to a crisis in the region that requires timely management and changing the current management style in the province. Therefore, proper management is necessary to deal with and reduce the damage of natural disasters. The management that is followed by developing countries is crisis management since they lack enough knowledge about future events and climate change and need to always wait for the disaster to occur and then manage the crisis. Nonetheless, the correct and timely forecasts of future weather conditions and climate change can lead to the most appropriate management of these events.

Experts and specialists believe that in the current conditions, such factors as poor management, inadequate economic, cultural, and 
political infrastructures, lack of a clear development strategy, non-competitiveness, partialism, policy instability, and disregard for industrial and economic developments have caused Iran to be incapable of achieving its true and worthy position in the world despite its abilities and capabilities, especially the necessary human resources. Reaching the right position requires the necessary infrastructures and prepared contexts for timely communication with up-to-date management knowledge, training skillful managers, respecting consulting and expert services, studies, research, and training programs. In this regard, creating an appropriate management mentality that can lead the community will have a great impact. Consequently, it is noteworthy that the main goal of natural hazard and disaster planning is to optimize crisis response activities and minimize the damage caused by them.

\section{Acknowledgments}

The authors would like to express their gratitude to the Iran Meteorological Organization and Governor of Hamedan Province for providing the required statistics and information.

\section{Conflict of Interests}

Authors have no conflict of interests.

\section{References}

1. Prudhomme C, Davies H. Assessing uncertainties in climate change impact analyses on the river flow regimes in the UK. Part 2: future climate. Clim Change 2009; 93(1): 197-222.

2. Wilby RL, Harris I. A framework for assessing uncertainties in climate change impacts: low-flow scenarios for the River Thames, UK. Water Resour Res 2006; 42(2): 1-10.

3. Wang H, Xiao W, Wang Y, Zhao Y, Lu F, Yang $\mathrm{M}$, et al. Assessment of the impact of climate change on hydropower potential in the Nanliujiang river basin of China. Energy 2019; 167: 950-9.

4. Türkeş M, Sümer UM, Demir İ. Re-evaluation of trends and changes in mean, maximum and minimum temperatures of Turkey for the period 1929-1999. Int J Climatol 2002; 22(8): 947-77.

5. Ashraf B, Alizadeh A, Mousavi Beigi M, Bannayan Aval M. Verification of temperature and precipitation simulated data by individual and ensemble performance of five AOGCM models for North East of Iran. Water Soil 2014; 28(2): 253-66 [In Persian].

6. Jahanbakhsh Asl S, Khorshiddoust A, Alinejad
$\mathrm{MH}$, Pourasghar F. Impact of climate change on precipitation and temperature by taking the uncertainty of models and climate scenarios (case study: Shahr Chay basin in Urmia). Hydro geomorphology 2016; 2(7): 107-22. [In Persian].

7. Ghandi A, Seyedian SM. Uncertainty analysis of rainfall projections (case study: Bojnord and Mashhad synoptic gauge station). J Water Soil Conservat 2017; 24(1): 189-204. [In Persian].

8. Khazaei MR, Khazaei H. Scenarios in climate change impact assessment on monthly stream-flow of Karun Basin. J Environ Sci Technol 2018; 20(1): 29-40. [In Persian].

9. Taban H, Zohrabi N, Nikbakht SA. Uncertainty assessment of GCM models for estimating rainfall and runoff of Dez Ulya basin under climate change. J Earth Space Phys 2018; 44: 89-102. [In Persian].

10. Wilby RL, Whitehead PG, Wade AJ, Butterfield D, Davis RJ, Watts G. Integrated modeling of climate change impacts on water resources and quality in a lowland catchment: River Kennet, UK. J Hydrol 2006; 330(1-2): 204-20.

11. Cameron D. An application of the UKCIP02 climate change scenarios to flood estimation by continuous simulation for a gauged catchment in the northeast of Scotland, UK (with uncertainty). J Hydrol 2006; 328(1-2): 212-26.

12. Graham LP, Hagemann S, Jaun S, Beniston M. On interpreting hydrological change from regional climate models. Clim Change 2007; 81(1): 97-122.

13. Fowler HJ, Ekström M. Multi-model ensemble estimates of climate change impacts on UK seasonal precipitation extremes. Int $\mathrm{J}$ Climatol 2009; 29(3): 385-416.

14. Chilkoti V, Bolisetti T, Balachandar R. Climate change impact assessment on hydropower generation using multi-model climate ensemble. Renewable Energy 2017; 109: 510-7.

15. Naz BS, Kao SC, Ashfaq M, Gao H, Rastogi D, Gangrade S. Effects of climate change on streamflow extremes and implications for reservoir inflow in the United States. J Hydrol 2018; 556: 359-70.

16. Wang GQ, Zhang JY, Xu YP, Bao ZX, Yang XY. Estimation of future water resources of Xiangjiang River Basin with VIC model under multiple climate scenarios. Water Sci Eng 2017; 10(2): 87-96.

17. Thompson JR, Laizé CL, Green AJ, Acreman MC, Kingston DG. Climate change uncertainty in environmental flows for the Mekong River. Hydrol Sci J 2014; 59(3-4): 935-54.

18. Xu K, Xu B, Ju J, Wu C, Dai H, Hu BX. Projection and uncertainty of precipitation extremes in the CMIP5 multimodel ensembles over nine major basins in China. Atmos Res 2019; 226: 122-37.

19. Andarzian B, Bannayan M, Steduto P, Mazraeh H, Barati ME, Barati MA, et al. Validation and testing 
of the AquaCrop model under full and deficit irrigated wheat production in Iran. Agr Water Manag 2011; 100(1): 1-8.

20. Krause P, Boyle DP, Bäse F. Comparison of different efficiency criteria for hydrological model assessment. Adv Geosci 2005; 5: 89-97.

21. Toor GS, Harmel RD, Haggard BE, Schmidt G. Evaluation of regression methodology with lowfrequency water quality sampling to estimate constituent loads for ephemeral watersheds in Texas. J Environ Qual 2008; 37(5): 1847-54.

22. Solomon S. The physical science basis: contribution of working group I to the fourth assessment report of the intergovernmental panel on climate change. Cambridge: Intergovernmental
Panel on Climate Change (IPCC), Climate Change; 2007.

23. Hashemi-Ana SK, Khosravi M, Tavousi T, Nazaripour H. Validation of AOGCMs capabilities for simulation length of dry spells under the climate change and uncertainty in Iran. Sci Res Quart Geographical Data 2017; 26(103): 43-58 [In Persian].

24. Gholampour Shemami Y, Majnoun Hosseini N, Bazrafshan J, Sharifzadeh F, Kanouni H. Assessing precipitation, and reference potential evapotranspiration in the current climate and under CORDEX climate change projections in major dry lands region of Kurdistan province. Iran J Soil Water Res 2020; 50(10): 2583-94 [In Persian]. 